\title{
UMA ANÁLISE DAS RESSALVAS DO TCE-PE NAS PRESTAÇÕES DE CONTAS EM PREFEITURAS MUNICIPAIS NO ESTADO DE PERNAMBUCO
}

\section{A ANALYSIS OF THE RESTRICTIONS FROM TCE-PE IN THE PROVISION OF ACCOUNTS IN THE CITY HALLS OF PERNAMBUCO ESTATE}

\section{UN ANÁLISIS DE LAS RESERVAS DEL TCE-PE EN LAS PRESTACIONES DE CUENTAS EN AYUNTAMIENTOS MUNICIPALES EN EL ESTADO DE PERNAMBUCO}

\section{FABRÍCIA PEREIRA CAVALCANTI SILVA}

Contadora; Especialista em Contabilidade e Controladoria UFPE; Mestranda em Ciências Contábeis da UFPE (PPGCC/UFPE); Professora da Universidade Federal Rural de

Pernambuco (UFRPE).

fabriciacavalcanti@uol.com.br

\section{JOSÉ FRANCISCO RIBEIRO FILHO}

Contador; Mestre em Ciências Contábeis pela FGV (RJ); Doutor em Ciências Contábeis pela USP/SP; Professor do Departamento de Ciências Contábeis da UFPE; Professor e

Coordenador do Mestrado em Ciências Contábeis pela UFPE (PPGCC/UFPE).

francisco.ribeiro@pq.cnpq.br

\section{RESUMO}

$\mathrm{O}$ artigo tem como objetivo analisar qualitativamente as ressalvas nas contas aprovadas pelo TCE-PE, e o que de fato elas representam: se entropia do sistema de controle, irresponsabilidade operacional ou falta de autonomia do gestor em liquidar pendências administrativas apontadas pelo TCE-PE, nos anos de 2000 a 2005, nos municípios da região metropolitana do Recife. Foi realizada uma pesquisa nos sítios do Governo de Pernambuco e no Tribunal de Contas do Estado de Pernambuco, no período de abril a maio de 2006. O universo da pesquisa compreendeu quatorze (14) prefeituras da região metropolitana do Recife. A amostra foi composta pelas prefeituras 


\section{repec}

Uma análise das ressalvas do TCE-PE nas prestações de contas em prefeituras municipais no Estado de Pernambuco

que, de 2000 a 2005, sofreram restrições nas prestações de contas pelo TCE/PE. A metodologia utilizada foi o estudo empírico-exploratório. Foram analisados 44 processos abertos pelo TCE, sendo que 20 destes não foram julgados, e, portanto, estavam sem pareceres na Internet. Concluiu-se que as ressalvas apresentadas nos pareceres do TCE-PE repetiram-se nos municípios, principalmente em 2001, apontando Falhas de Controles Internos.

Palavras-chave: Ressalvas; Entropia no Sistema de Controle; Pareceres; Internet.

\section{ABSTRACT}

The objective of this article is to analyze the quality restrictions in the approved counts of TCE-PE and what they represent, moreover; find out if there are problems in the system control, problems in the operational irresponsibility or lack of autonomy from the acting manager to finalize the administrative pendencies brought by the TCE-PE from the years 2000 to 2005 . This study would be covering the cities in the metropolitan region of Recife. There has been research done on the government websites of Pernambuco and in the Court of Accounts from April to May of 2006. Overall, this research includes fourteen (14) city halls of the metropolitan region of Recife. This sample study has been put together by the city halls during the years 2000 to 2005 in which all the city halls suffered restrictions in the counts hosted by TCE/PE. The methodology used was an empiric-explanatory study. Forty four opened processes have been analyzed by the TCE, from which 20 have not been researched; therefore, the result did not come to a legal conclusion on the website. It has therefore been concluded that the presented correction in the legal results from the TCE-PE have been repeated in the cities- mainly in 2001, showing failure from Internal Control.

Keywords: Correction; Entropy in the System Control; Legal Opinion; Internet.

\section{RESUMEN}

El artículo tiene como objetivo analizar cualitativamente las reservas en las cuentas aprobadas por el TCE-PE, y lo que de hecho ellas representan: entropía del sistema de control, irresponsabilidad operacional o falta de autonomía del gestor en liquidar pendencias administrativas señaladas por el TCE-PE, en los años de 2000 a 2005, en los municipios de la región metropolitana de Recife. Fue realizada una pesquisa en los sitios del Gobierno de Pernambuco y en el Tribunal de Cuentas del Estado de Pernambuco, en el período de abril a mayo de 2006. El universo de la pesquisa 
comprendió catorce (14) ayuntamientos de la región metropolitana de Recife. La muestra fue compuesta por los ayuntamientos que, de 2000 a 2005, sufrieron restricciones en las prestaciones de cuentas por el TCE/PE. La metodología utilizada fue el estudio empírico-exploratorio. Fueron analizados 44 procesos abiertos por el TCE, siendo que 20 de éstos no fueron juzgados, y, por tanto, estaban sin parecer en la Internet. Se concluyó que las reservas presentadas en los pareceres del TCE-PE se repitieron en los municipios, principalmente en 2001, señalando Fallos de Controles Internos.

Palabras-Clave: Reservas; Entropía en el Sistema de Control; Pareceres; Internet.

\section{INTRODUÇÃO}

Sabe-se, à luz do ordenamento constitucional brasileiro e também pelo acúmulo de saberes e procedimentos técnicos pertinentes, que a prestação de contas a cargo do Poder Executivo é alvo de controle por parte dos Tribunais de Contas, a fim de atender aos preceitos requeridos e evidenciar quaisquer desvios de finalidade das tarefas, a cargo dos gestores públicos no Brasil.

$\mathrm{Na}$ conjuntura atual, em que o perfil dos cidadãos brasileiros tem mudado, no sentido de se configurar uma postura mais crítica e, também, exigente, no sentido do acompanhamento dos atos da gestão pública, o julgamento das contas públicas ressurge como uma ferramenta fundamental no processo de controle da atividade financeira do Estado. Dessa forma, cresce de modo contínuo o interesse no meio civil pela matéria, e a preocupação dos poderes públicos de prover informações eficazes, mediante um acompanhamento mais qualitativo dos processos operacionais. No ambiente mais crítico em que estamos inseridos, fica evidente a necessidade de um adequado detalhamento das causas e efeitos sobre as contas prestadas pelos órgãos da administração pública, de maneira que todos nós possamos obter informações relevantes relacionadas à eficiência e responsabilidade dos gestores na condução da coisa pública.

Neste contexto, o Tribunal de Contas, órgão independente e autônomo, de controle externo, assume papel indispensável na fiscalização dos atos gerenciais do governo, permitindo avaliar as causas e sua significância para a vida em coletividade. Heraldo da Costa Reis (2004, p.179) afirma que depois de tanto ouvir e ler nos jornais perguntas sobre o que é feito com o dinheiro que as entidades governamentais arrecadam, teve a iniciativa de alertar os contadores da contabilidade governamental que as informações produzidas de contabilidade já não satisfazem às exigências de uma administração moderna, em razão de utilização de técnica já superada pela evolução da própria teoria contábil aplicada às entidades governamentais. $E$ vai mais além, ao 


\section{repec}

Uma análise das ressalvas do TCE-PE nas prestações de contas em prefeituras municipais no

Estado de Pernambuco

lançar uma pergunta: de que maneira os governos da União, dos Estados, do Distrito Federal e dos Municípios poderiam ser auxiliados na solução dessas questões, e, como conseqüência, satisfazer o contribuinte para que este possa participar também desses governos, ainda que de forma indireta?

Vê-se desde já a necessidade que os usuários da administração pública possuem de obter informações a respeito da prestação de contas governamental. Por deferência, o mesmo se aplica ao julgamento que é dado pelo Tribunal de Contas. Então, este é o aspecto da maior importância: dar à população as razões que determinaram as rejeições e ressalvas nas contas apresentadas pelo governo. Hoje, o povo brasileiro necessita de informações oportunas, precisas e adequadas sobre a economia, política e gestão pública, haja vista a estabilização da moeda, a abertura de novos mercados, a formação de blocos econômicos, e, principalmente, a globalização. No passado, quando o volume de recursos financeiros na área pública não era tão parco e não havia tanta excelência nos processos de prestação de contas, devido a uma série de limitações, bastavam os decretos e portarias ministeriais para a resolução dos problemas internos. Atualmente, porém, isso não é mais possível. Os princípios da moralidade, publicidade, eficiência contidos no artigo 37 do texto constitucional sobrepõem-se aos mandos dos gestores e aliam-se aos anseios da população.

A pesquisa em foco destina-se a apresentar as ressalvas do Tribunal de Contas -PE nas contas aprovadas das prefeituras da região metropolitana de Pernambuco, compreendidas no período do ano de 2000 a 2005, onde se busca evidenciar os fatores determinantes de tais pendências. O trabalho terá seu desenvolvimento fundamentado nos princípios da Administração Pública, notadamente, a publicidade, moralidade e eficiência; na Seção IX - DA FISCALIZAÇÃO CONTÁBIL, FINANCEIRA E ORÇAMENTÁRIA, da CF/88; nas diretrizes da Lei de Responsabilidade Fiscal (101/00); na Lei n. ${ }^{\circ}$ 4.320/64 - Direito Financeiro; na Constituição Estadual de Pernambuco; e nas Leis Ordinárias dos Municípios envolvidos.

\section{A CONTROLADORIA NA GESTÃO PÚBLICA}

"Controladoria, termo de difícil definição, no entanto, é feita desde os primórdios. Controladoria é, portanto, a busca pelo atingimento do ótimo em qualquer ente, seja ele público ou privado, e o algo mais, procurado pelo conjunto de elementos que compõem a máquina de qualquer entidade", defende Slomski (2005, p.15).

Segundo Martins (2002, p. 204), os estudos dos sistemas de controle no Brasil revelam que desde 1922 há o envolvimento da ação de três órgãos clássicos: o Tesouro Nacional, a Contadoria Geral da República e o Tribunal de Contas em favor da arrecadação das Receitas Públicas e no pagamento das Despesas públicas processa- 
das; centralização do registro dos atos orçamentários; bem como o acompanhamento da execução orçamentária mediante a coordenação, orientação, direção e fiscalização de todos os serviços de escrituração e contabilidade; e, finalmente, a realização do julgamento das contas dos responsáveis por dinheiros ou bens públicos e sobre a legalidade dos contratos celebrados.

A constituição brasileira de 1988 estabelece que a fiscalização contábil, financeira e orçamentária terá como objetivo os aspectos da legalidade, legitimidade, economicidade, aplicação de subvenções e renúncia de receitas, e que esta fiscalização será exercida pelo Poder Legislativo, mediante controle externo, e pelo Sistema de Controle Interno de cada poder.

Dessa forma, observamos que hoje, de fato, existem três níveis de controle na gestão pública: o externo, executado pelos Tribunais de Contas; o interno, praticado em cada um dos poderes; e o interno-integrado, mantido em conjunto pelos três poderes, face às inovações da tecnologia da informação surtida ao longo desses anos.

Seguindo o professor Martins (2002, p. 208), o controle externo é da competência do Poder Legislativo, exercido com o auxílio dos Tribunais de Contas; o controle interno visa proteger e salvaguardar os bens e outros ativos contra fraudes, perdas ou erros não intencionais, além de assegurar o grau de confiabilidade das informações contábeis e financeiras. Assim, afirma que as normas constitucionais ao tratar de controle interno obrigam a prestação de contas de qualquer pessoa física ou jurídica, pública ou privada, que utilize, arrecade, guarde, gerencie, ou administre dinheiros, bens e valores públicos ou pelos quais a União responda, ou que, em nome desta, assuma obrigações de natureza pecuniária.

O ilustre professor vai mais além, definindo o controle interno-integrado como sendo uma tarefa do Estado como pessoa jurídica de direito público coordenando as atividades internas de cada entidade ou conjunto dos três poderes visando proteger permanente e continuamente o patrimônio público.

Slomski, (2005, p. 15) adverte:

é premente a existência de um órgão que faça essa concertação (ato de produzir sinfonia) - onde todos os instrumentos toquem de maneira isolada, porém sob a mesma batuta, ou seja, que todos trabalhem buscando um só objetivo, a maximização do resultado global da entidade.

Neste contexto, insere-se a participação fundamental dos serviços de contabilidade e auditoria vinculados aos órgãos centrais de controle, gerando relatórios finalísticos sobre a economicidade, eficiência e eficácia praticadas em cada ente ou órgão público.

Todavia, devemos reconhecer que os demonstrativos de contabilidade e auditoria na gestão pública pouco contribuem para fortalecer o sistema de controle interno- 
integrado do governo, em função dos termos essencialmente técnicos. Muitas vezes, além de ininteligíveis para o cidadão comum, torna-se um entrave nas tomadas de decisões para alguns gestores municipais, notadamente, que não possuem formação técnica adequada para entender as ações ali propostas.

Outrossim, o que observamos é que os relatórios financeiros elaborados pela administração financeira e desassociados da Contabilidade trazem a racionalização do processo da execução orçamentária e possibilitam ao gestor público uma relativa independência no poder de gasto e mando. Com isso, a contabilidade tende a burocratizarse pelo princípio da legalidade, já que necessita da veracidade e fidedignidade dos dados e registros produzidos pelo ente. $E$ isto é indicador de retrocesso, já que ligadas à função fazendária, a auditoria e a contabilidade encerram suas atividades nos atos a quem se subordinam e não avançam nas práticas de melhoramento de seus demonstrativos nos aspectos qualitativos da informação contábil. Ou seja, a contabilidade e auditoria enchem-se de formalismo melancolicamente.

Martins (2002, p.207) traz alguns questionamentos sobre os relatórios produzidos pela contabilidade e auditoria pública, e que, se respondidos em sua maioria de forma afirmativa, estamos ainda num estágio bem anterior à Constituição de 1988, e caso contrário, estamos diante do século XXI atendendo os princípios constitucionais:

- o formalismo prevalece sobre a essência?;

- o rigor técnico está voltado para os aspectos legais e meramente burocráticos?;

- os funcionários não estão habilitados para atuar com a auditoria como ferramenta de apoio à decisão?

- o órgão de auditoria e contabilidade é subordinado administrativamente àqueles a quem deve controlar?

- o controle enfatizava a legalidade independentemente dos aspectos econômicos das ações administrativas?

- a administração somente se preocupa com os aspectos financeiros do gasto e nuNca ou quase nunca com os aspectos econômicos?

Em suma, percebe-se a fragilidade de controle interno por que passam os entes governamentais provocada pelo enrijecimento legal do sistema, muito embora existam técnicas e procedimentos gerenciais que podem miniminizar a distorção causada entre os relatórios de contabilidade e auditoria públicos, e as necessidades de informações dos usuários participantes de um mundo cada vez mais informívero (que suscitam informações em tempo real). 


\section{repc}

\section{AS AUDITORIAS NA ÁREA GOVERNAMENTAL E OS TIPOS DE PARECER}

O controle externo e o interno, órgãos responsáveis pelo acompanhamento, avaliação e controle das contas públicas utilizam-se da técnica contábil - Auditoria - para realizar as tarefas que foram submetidas pela Constituição Federal de 1988.

Os procedimentos de Auditoria visam garantir a probidade, a legalidade, legitimidade dos atos praticados pela gestão pública. O professor Sérgio Jund (2002, p. 112) menciona que a auditoria é realizada na máquina administrativa em todas as unidades e entidades públicas, devendo ser observado os aspectos relevantes relacionados à avaliação dos programas de governo e da gestão pública.

Como preceitua a Instrução Normativa Federal 01/2001 da Secretaria Federal de Controle, a auditoria governamental consiste no conjunto de técnicas que visa avaliar a administração pública, pelos processos e resultados gerenciais, e a aplicação de recursos públicos por entidades de direito público e privado, mediante a confrontação entre uma situação encontrada com um determinado critério técnico operacional ou legal.

Assim, Sérgio Jund (2002, p.112) acentua: que se trata de uma importante técnica de controle do Estado na busca da melhor alocação de seus recursos, não só atuando para corrigir os desperdícios, a improbidade, a negligência, e a omissão, mas principalmente antecipando-se a essas ocorrências, buscando garantir os resultados pretendidos, além de destacar os impactos e benefícios sociais advindos.

Não obstante, tal instrumento menciona que a opinião do auditor público deve ser expressa por meio de Relatório, Parecer, Certificado ou Nota.

O certificado de auditoria é emitido na verificação contábil, financeira, orçamentária, operacional e patrimonial das entidades da administração direta ou indireta, no tocante aos princípios da legalidade, legitimidade, economicidade, e aplicação de subvenções e renúncia de receitas, como acentua o Professor Sérgio Jund (2002 p.423):

O Certificado de Auditoria será emitido na verificação das contas dos responsáveis pela aplicação, utilização ou guarda de bens e valores públicos, e de todo aquele que der causa à perda, subtração ou estrago de valores, bens e materiais de propriedade ou responsabilidade da União.

Os tipos de certificados conforme a instrução normativa 01/2001 da Secretaria Federal de Controle são:

- Certificado de Regularidade - É emitido quando o auditor formar a opinião de que os recursos públicos foram empregados adequadamente observando os princípios da legalidade, legitimidade e economicidade; 
- Certificado de Regularidade com Ressalvas - É emitido quando o auditor constata falhas, omissões ou impropriedades de natureza formal no cumprimento das normas e diretrizes governamentais, quanto à legalidade, legitimidade e economicidade e que, pela sua relevância ou imaterialidade, não caracterizem irregularidade de atuação dos agentes responsáveis;

- Certificado de Irregularidade - É quando o auditor verifica a inobservância da aplicação dos princípios da legalidade, legitimidade, economicidade, constatando a existência de desfalque, alcance, desvio de bens ou outra irregularidade de que resulte prejuízo quantificável para a Fazenda Nacional e/ ou comprometam, substancialmente, as demonstrações financeiras e a respectiva gestão dos agentes responsáveis, no período ou exercício examinado.

A mesma instrução normativa do Sistema de Controle Interno requer ainda o atendimento dos seguintes requisitos estruturais na emissão do certificado de auditoria:

I. indicar número de processo, exercício examinado, unidade gestora/entidade examinada;

II. citar, no parágrafo inicial, o escopo do trabalho em função do tipo de auditoria realizada;

III. registrar no parágrafo intermediário, as impropriedades ou irregularidades que:

a) caracterizem a inobservância de normas legais e regulamentares;

b) afetem a gestão ou situação examinada;

c) comprometam a economicidade, legalidade e legitimidade da gestão ou situação examinada;

d) resultem ou não em prejuízo à Fazenda Nacional.

IV. observado o contido no parágrafo intermediário, concluir, no parágrafo final, emitindo opinião quanto à regularidade, ou não, da gestão examinada;

V. conter data do certificado correspondente ao dia de sua emissão;

VI. conter assinatura do coordenador-geral ou gerente regional de controle interno, ou, ainda, autoridades hierárquicas equivalentes nos órgãos e unidades setoriais do Sistema de Controle Interno do Poder Executivo Federal; e

VII. no caso de auditoria contábil, conter o nome e o número de registro no Conselho Regional de Contabilidade do servidor do Sistema de Controle Interno do Poder Executivo Federal que examinou as demonstrações financeiras.

Neste diapasão, as Resoluções 820/97 e 830/98 do Conselho Federal de Contabilidade estabelecem a estrutura do modelo padrão do parecer de auditoria, como a reprodução a seguir: 


\begin{tabular}{|l|}
\hline $1^{\circ} \S$ - INICIAL ou INTRODUTÓRIO \\
- Identificação das demonstrações contábeis \\
- Definição da responsabilidade da administração \\
- Definição da responsabilidade do auditor \\
\hline $2^{\circ} \S$ - INTERMEDIÁRIO ou EXTENSÃO \\
- Descrição concisa dos trabalhos executados \\
\hline $3^{\circ} \S$ - DA OPINIÃO \\
- Expressa a opinião do auditor: \\
- Sem ressalva \\
- Com ressalva \\
• Adverso \\
• Abstenção de opinião \\
\hline PARÁGRAFO DE ÊNFASE ${ }^{* *}$ \\
- Quando houver incerteza em relação a fato relevante "utilizado \\
somente para parecer sem ressalva" (após o $\S$ de opinião) \\
** Não integra a estrutura do parecer padrão \\
\hline
\end{tabular}

\section{Quadro 1 - Modelo de parecer emitido pelo Conselho Federal de Contabilidade (CFC)}

Dessa forma, o professor Sérgio Jund adverte (2002, p. 411) que o auditor ao emitir o parecer com ressalva, adverso ou com abstenção de opinião deve ser incluída descrição clara de todas as razões que fundamentou o seu parecer e, se praticável, a quantificação dos efeitos sobre as demonstrações contábeis. Neste contexto preceitua que o conjunto das informações sobre o assunto objeto da ressalva, constante no parecer e nas notas explicativas, deve permitir aos usuários claro entendimento de sua natureza e seus efeitos nas demonstrações contábeis, particularmente sobre as posições patrimoniais, financeiras e o resultado das operações.

\section{A PESQUISA}

Foi realizada uma pesquisa nos sítios do governo de Pernambuco e no Tribunal de Contas do Estado de Pernambuco, no período de abril a maio de 2006, visando obter informações para os seguintes aspectos:

- Quais municípios fazem parte da região metropolitana de Pernambuco;

- A quantidade de pareceres prévios das prestações de contas anuais nos municípios da Região Metropolitana nos anos de 2000 a 2005;

- Levantamento do percentual de aprovações com ressalvas pelo TCE-PE, nas contas anuais das prefeituras de 2000 a 2005; 
- Quais prefeituras tiveram suas contas aprovadas com ressalvas nesse período;

- Análise das ressalvas nas contas aprovadas das prefeituras da Região metropolitana de Pernambuco, de 2000 a 2005;

\section{RESULTADOS DA PESQUISA}

A pesquisa revelou os seguintes resultados:

Parâmetro 1: As prefeituras da Região Metropolitana de Pernambuco

\begin{tabular}{|l|l|}
\hline Regiões de Pernambuco & Região Metropolitana do Recife \\
\hline Agreste & Araçoiaba \\
\hline Zona da Mata & Abreu e Lima \\
\hline Sertão & Camaragibe \\
\hline São Francisco & Cabo de Santo Agostinho \\
\hline Região Metropolitana do Recife & Igarassu \\
\hline & Ipojuca \\
\hline & Itapissuma \\
\hline & Itamaracá \\
\hline & Jaboatão \\
\hline & Moreno \\
\hline & Olinda \\
\hline & Paulista \\
\hline & Recife \\
\hline & São Lourenço da Mata \\
\hline
\end{tabular}

\section{Quadro 2 - Relação das prefeituras analisadas.}

Parâmetro 2: As prefeituras que tiveram as contas aprovadas com ressalvas entre 2000 e 2005 :

\begin{tabular}{|l|l|}
\hline Municípios & Período em que constaram ressalvas \\
\hline Ipojuca & 2000 e 2001 \\
\hline Itapissuma & 2001 e 2002 \\
\hline Jaboatão & 2000 \\
\hline Moreno & 2000,2001 e 2002 \\
\hline Olinda & 2001 \\
\hline
\end{tabular}

Quadro 3 - Prefeituras que obtiveram pareceres com ressalva no período 2000 
- 2005. Observação: $O$ julgamento das contas pelo TCE-PE é realizado mediante abertura de processos em ano subseqüente ao exercício analisado. Portanto, a pesquisa no site inicia-se em 2001 e vai até 2006 e por número de processo.

Parâmetro 3: Os processos do TCE-PE para julgamento das contas por município:

\begin{tabular}{|c|c|c|c|c|}
\hline \multicolumn{5}{|l|}{ IPOJUCA } \\
\hline $\begin{array}{l}\mathrm{N}^{\circ} \text { Processo } \\
\text { T.C.E }\end{array}$ & N.Deliberação & $\begin{array}{l}\text { Qde. } \\
\text { processos } \\
\text { abertos }\end{array}$ & Exercício & Observações \\
\hline 0101977-2 & 0300484 & 20 & 2000 & - \\
\hline 0201561-4 & 0301149 & 19 & 2001 & - \\
\hline 0301620-1 & 0501808 & 26 & 2002 & $\begin{array}{l}\text { Não foi informado no } \\
\text { sistema }\end{array}$ \\
\hline 0420005-6 & 0501226 & 19 & 2003 & - \\
\hline 0520018-0 & s/julgamento & 12 & 2004 & Nada Consta no sistema \\
\hline 0620018-7 & s/julgamento & 52 & 2005 & Nada Consta no sistema \\
\hline \multicolumn{5}{|l|}{ ITAPISSUMA } \\
\hline 0101901-6 & s/julgamento & 03 & 2000 & $\begin{array}{l}\text { Falta de transparência } \\
\text { eleições }\end{array}$ \\
\hline 0201208-0 & 0301113 & 01 & 2001 & - \\
\hline 0301666-3 & 0401545 & 06 & 2002 & - \\
\hline $0302317-5$ & 0401545 & - & 2002 & - \\
\hline 0203851-5 & 0401545 & - & 2002 & - \\
\hline 0402495-3 & s/julgamento & 02 & 2003 & Nada Consta no sistema \\
\hline 0501168-1 & s/julgamento & 05 & 2004 & Nada Consta no sistema \\
\hline 0610021-1 & s/julgamento & 03 & 2005 & Nada Consta no sistema \\
\hline \multicolumn{5}{|l|}{ JABOATÃO } \\
\hline 0102543-0 & 0301506 & 101 & 2000 & Não constam as ressalvas \\
\hline 0203289-2 & s/julgamento & 252 & 2001 & S/informação \\
\hline 0301642-0 & s/julgamento & 94 & 2002 & $\begin{array}{l}\text { Transparência bolsa } \\
\text { estudos }\end{array}$ \\
\hline 0420028-7 & s/julgamento & 181 & 2003 & S/informação \\
\hline 0520012-0 & s/julgamento & 60 & 2004 & S/informação \\
\hline $0610015-6$ & s/julgamento & 120 & 2005 & Contas FMS,FMAS,FMCA \\
\hline \multicolumn{5}{|l|}{ MORENO } \\
\hline 0101974-0 & 0400180 & 05 & 2000 & - \\
\hline 0202818-9 & 0300823 & 27 & 2001 & - \\
\hline
\end{tabular}


Uma análise das ressalvas do TCE-PE nas prestações de contas em prefeituras municipais no Estado de Pernambuco

\begin{tabular}{|l|l|l|l|l|}
\hline $0301759-0$ & 0500281 & 06 & 2002 & - \\
\hline $0420019-6$ & s/julgamento & 03 & 2003 & Nada Consta no sistema \\
\hline $0501572-8$ & s/julgamento & 03 & 2004 & Nada Consta no sistema \\
\hline 0620002-3 & s/julgamento & 41 & 2005 & Nada Consta no sistema \\
\hline OLINDA & & & & \\
\hline $0101816-4$ & s/julgamento & 112 & 2000 & Fundo de Pensão \\
\hline $0100129-2$ & s/julgamento & - & 2000 & Apenso \\
\hline $0201311-3$ & 0401495 & 48 & 2001 & - \\
\hline $0301150-1$ & s/julgamento & 78 & 2002 & Nada Consta no sistema \\
\hline $0402471-0$ & s/julgamento & 82 & 2003 & Nada Consta no sistema \\
\hline $0501253-3$ & s/julgamento & 80 & 2004 & Nada Consta no sistema \\
\hline S/número & s/julgamento & 97 & 2005 & Em aberto \\
\hline
\end{tabular}

\section{Quadro 4 - Processos analisados por prefeitura I.}

\section{Parâmetro 4: As ressalvas por processo em cada município}

\begin{tabular}{|c|c|c|}
\hline \multicolumn{3}{|r|}{ IPOJUCA } \\
\hline Processo & Exercício & Ressalvas/Recomendações \\
\hline 0101977-2 & 2000 & 1. Falhas de Procedimento do controle interno. \\
\hline 0201561-4 & 2001 & $\begin{array}{l}\text { Contabilizar corretamente os valores transferidos para o Poder Legislativo; } \\
\text { Observar, quando da realização de despesas com abastecimento dos ve- } \\
\text { ículos, os termos da Decisão TC } n .^{\circ} 329 / 92 \text { deste Tribunal; } \\
\text { 3. Preservar o material decorrente das despesas com publicidade, e ane- } \\
\text { xar a respectiva documentação à prestação de contas, haja vista o dispos- } \\
\text { to no artigo } 5^{\circ} \text { da Resolução TC } n .^{\circ} 05 / 91 \text {. }\end{array}$ \\
\hline 0301620-1 & 2002 & 1. Não Constam as ressalvas para o número de deliberação 0501808. \\
\hline 0420005-6 & 2003 & $\begin{array}{l}\text { 1. Que adotem as recomendações constantes no item "5.3" do Laudo de } \\
\text { Auditoria Técnica de Obras e Serviços de Engenharia às fls. } 4.652 \text { e no item } \\
\text { "06" do Relatório Preliminar às fls. 8953, cujas cópias Ihes serão enviadas; } \\
\text { 2. Determinar que seja encaminhada cópia do Laudo de Auditoria Técnica } \\
\text { de Obras e Serviços de Engenharia ao Tribunal de Contas da União, a fim } \\
\text { de que lhe sirva de subsídio para futura auditoria. }\end{array}$ \\
\hline \multicolumn{3}{|r|}{ ITAPISSUMA } \\
\hline 0201208-0 & 2001 & 1. Falhas de Procedimento do controle interno. \\
\hline 0301666-3 & 2002 & 2. Denúncia tomada como improcedente. \\
\hline \multicolumn{3}{|r|}{ JABOATÃO } \\
\hline 0102543-0 & 2000 & 1. Falhas de Procedimento do controle interno. \\
\hline \multicolumn{3}{|r|}{ MORENO } \\
\hline
\end{tabular}




\begin{tabular}{|c|c|c|}
\hline 01019740 & 2000 & $\begin{array}{l}\text { 1. Elaborar e encaminhar as prestações de contas dos Fundos Especiais, } \\
\text { nos moldes traçados pela Resolução TC } \text { n. }^{\circ} 06 / 91 \text {; } \\
\text { 2. Aprimorar os controles relativos às aquisições de combustíveis; } \\
\text { 3. Exigir maior detalhamento nas notas fiscais e faturas dos serviços de saúde; } \\
\text { 4. Aprimorar os controles e a aplicação dos recursos do FUNDEF; } \\
\text { 5. Aprimorar os controles dos demais Fundos Especiais; } \\
\text { 6. Encaminhar as prestações de contas das subvenções sociais nos mol- } \\
\text { des traçados pela Resolução TC } n^{\circ} 05 / 93 \text {; } \\
\text { 7. Que sejam desentranhadas dos autos às fls. } 625 \text { a } 649 \text { e encaminhadas } \\
\text { ao Ministério Público do Estado de Pernambuco, para que tome ciência } \\
\text { dos fatos apurados pela equipe de auditoria. }\end{array}$ \\
\hline 0301759-0 & 2002 & $\begin{array}{l}\text { 1. Que a contabilização da despesa do FUNDEF possibilite a geração dos } \\
\text { relatórios gerenciais citados na Resolução TC n. }{ }^{\circ} \text { 14/2001, viabilizando o } \\
\text { controle da aplicação dos recursos; } \\
\text { 2. Que se dê maior atenção ao limite previsto no parágrafo único do art. } 22 \\
\text { da Lei de Responsabilidade Fiscal; } \\
\text { 3. Que seja evitada a realização de despesas com recursos do FUNDEF } \\
\text { que não estejam amparadas pelas normas estabelecidas pelas Leis Fede- } \\
\text { rais n. }{ }^{\circ} \text { S } 9.424 / 96 \text { e 9.394/96; } \\
\text { 4. Que se adotem mecanismos de conferência da documentação fiscal } \\
\text { comprovante das despesas realizadas, evitando o acatamento quando } \\
\text { presentes indícios de invalidação daquela; } \\
\text { 5. Que sejam utilizados os livros Diário e Razão e, por conseguinte, que se } \\
\text { adote o método das partidas dobradas; } \\
\text { 6. Que sejam envidados esforços no sentido do pleno recolhimento, a } \\
\text { quem de direito, dos valores relativos à previdência social; }\end{array}$ \\
\hline \multicolumn{3}{|r|}{ OLINDA } \\
\hline 0201311-3 & 2001 & $\begin{array}{l}\text { 1. Consolidar as contas dos fundos municipais e da Prefeitura para fins de } \\
\text { apuração da receita corrente líquida e para o cálculo de índices legalmen- } \\
\text { te estabelecidos; } \\
\text { 2. Publicar os livros contábeis em tempo hábil após o encerramento do } \\
\text { exercício a fim de prevenir possíveis perdas de informações; } \\
\text { 3. Elaborar projeto de lei que delegue o ordenamento da despesa para o } \\
\text { Secretário e demais agentes do Poder Executivo; } \\
\text { 4. Levantar o débito total da Prefeitura para com o fundo de Pensão, face } \\
\text { à ausência de sua devida contabilização como dívida fundada; } \\
\text { 5. Definir legalmente as atribuições dos cargos técnico-pedagógicos cria- } \\
\text { dos pela Lei n. }{ }^{\circ} \text {-074/97; } \\
\text { 6. Realizar a previsão da despesa ou, sendo o servidor questionado sobre sua } \\
\text { participação, proceder ao rateio dos gastos em folha, mediante adesão, quan- } \\
\text { do da realização de festividades como as de fim de ano ou dia do servidor. }\end{array}$ \\
\hline
\end{tabular}

Quadro 5 - Processos identificados com ressalvas.

\section{Observações gerais sobre a pesquisa}

Observou-se da análise da pesquisa que as prestações de contas das prefeituras examinadas, anualmente, sofrem ressalvas, tendo em vista que de 2000 a 2005 foram 


\section{repc}

Uma análise das ressalvas do TCE-PE nas prestações de contas em prefeituras municipais no

Estado de Pernambuco

abertos 32 processos pelo TCE/PE, nesses municípios. Contudo, a maioria dos processos de 2003 a 2005, representando 63\% da amostra, está sem julgamento, dificultando uma depuração mais detalhada dos resultados da pesquisa. Vale ressaltar que 01(um) processo de 2005 não foi cadastrado no sistema, e por isso ainda não possui número.

As ressalvas discriminadas nas deliberações dos processos divulgados pelo sítio do TCE/PE, em sua estrutura, apresentam-se de forma bastante simplificada. Foram encontrados processos com ressalvas omitidas em número de 04 (quatro), representando 36\% dos pareceres investigados. Em 18\% dos processos, as deliberações fazem referência a leis, normas ou procedimentos legais; entretanto, sem informar as recomendações necessárias em vista do parecer. Em 46\% dos processos o parecer detalha as ressalvas.

Em relação às ressalvas propriamente ditas, $20 \%$ se repetiram num mesmo município. Em prefeituras diferentes, tivemos as seguintes classificações:

\begin{tabular}{|l|c|c|c|c|c|}
\hline \multirow{2}{*}{ Discriminação das Ressalvas } & \multicolumn{6}{|c|}{ Quantidade de Ressalvas por processos } & \multirow{2}{*}{$\begin{array}{c}\text { Totais das } \\
\text { Ressalvas }\end{array}$} \\
\cline { 2 - 6 } & $\mathbf{2 0 0 0}$ & $\mathbf{2 0 0 1}$ & $\mathbf{2 0 0 2}$ & $\mathbf{2 0 0 3}$ & \\
\hline 1. Falhas no Controle Interno & 04 & 08 & 02 & 01 & 15 \\
\hline 2. Imperícia Contábil & - & 03 & 01 & - & 04 \\
\hline 3. Inversão da fase da Despesa & 01 & 02 & 01 & - & 04 \\
\hline $\begin{array}{l}\text { 4. Erro Circunstancial Fiscal } \\
\text { (Apropriação indébita) }\end{array}$ & 01 & - & 01 & - & 02 \\
\hline 5. Não observância Legal & & 01 & 01 & - & 02 \\
\hline 6. Formalização documental & 03 & 03 & - & - & 06 \\
\hline TOTAL GERAL & 09 & 17 & 06 & 01 & 33 \\
\hline
\end{tabular}

Quadro 6 - Ressalvas Identificadas.

Abaixo é apresentado um gráfico relaciona em termos percentuais o tipo da ressalva e sua quantidade total nos processos examinados anualmente.

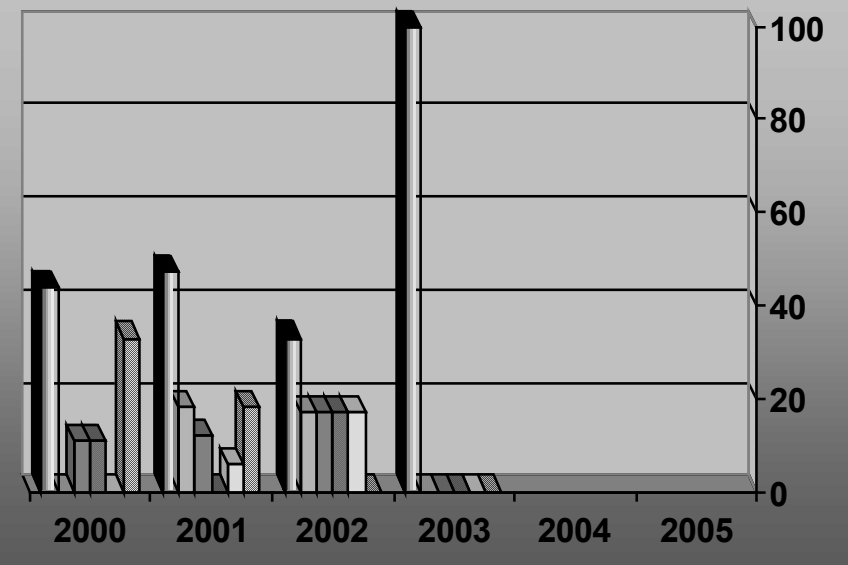

$\square$ Falhas controle interno $\square$ Contabilização $\square$ Inversão despesa $\square$ Erro circunstancial

$\square$ Reserva Legal

\section{Gráfico 1 - Tipos de Ressalvas}




\section{CONSIDERAÇÕES FINAIS}

As situações que ensejaram a emissão de Certificados de Auditoria regulares com ressalvas pelo TCE/PE, nas prefeituras da Região Metropolitana do Recife, no período compreendido de 2000 a 2005 consubstanciado pela pesquisa, foram:

- Falhas nos procedimentos de controle interno percebidos em todos os processos e em todos os anos, revelando assim entropia no sistema de controle;

- Formalização Documental, indicando o correto preenchimento de notas fiscais e empenhos;

- Não-observância dos dispositivos legais, referindo-se sobretudo ao limite de gastos contido no artigo 22 da Lei de Responsabilidade Fiscal;

- Imperícia Técnica Contábil, fazendo menção à elaboração de livros e preenchimento de documentos fiscais, bem como à aplicação do método das partidas dobradas;

- Inversão da Fase da Despesa Pública;

- Erro circunstancial, pela apropriação indébita de tributos na fonte, e não recolhido aos cofres públicos.

Pelo exposto pode-se observar que o Tribunal de Contas do Estado, por meio de Auditoria de Avaliação da Gestão, comprova a legalidade e legitimidade dos atos e fatos administrativos das prefeituras observadas na amostra, emitindo pareceres com ressalvas, em face de impropriedades, falhas ou omissões, cujos efeitos não caracterizam irregularidades de atuação dos agentes responsáveis.

Não obstante, as falhas nos procedimentos de controle interno são observadas em $45 \%$ do total das ressalvas analisadas, denotando enfraquecimento do sistema do controle pela não-garantia de resultados operacionais satisfatórios exigidos pelos princípios da economicidade, eficácia e eficiência na administração pública.

É ainda relevante ressaltar que $27 \%$ dos processos não identificaram os fatores das falhas de controle interno. Ou seja, os pareceres com ressalvas não detalham os motivos que levaram a classificá-la como impropriedade.

\section{CONCLUSÃO}

Por todo o exposto conclui-se que as ressalvas apresentadas nos pareceres dos auditores do Tribunal de Contas foram emitidas ao se constatarem situações impróprias. As análises indicaram as circunstâncias envolvidas no caso de julgamento de forma ampla e não permitem uma inferência mais específica sobre o grau de intencionalidade em praticar atos de má gestão, que redundaram nas ressalvas indicadas. No entanto, considerando-se a freqüência e vinculação de atos que ocasionaram as ressalvas para as Prefeituras indicadas, 


\section{repec}

Uma análise das ressalvas do TCE-PE nas prestações de contas em prefeituras municipais no

Estado de Pernambuco

percebe-se uma repetição dos mesmos erros, ao longo do tempo, sugerindo-se certo desinteresse pelo aperfeiçoamento do sistema de controle interno nas Prefeituras analisadas.

\section{REFERÊNCIAS}

BRASIL, Constituição da República Federativa.

BRASIL, Lei Complementar Federal n 101, de 04 de Maio de 2000.

BRASIL, Lei Federal n 4320, de 17 de Março de 1964.

ALMEIDA, Marcelo Cavalcanti. Auditoria: Um curso Moderno e Completo. São Paulo: Atlas, 1996.

CHIMENTI, Ricardo Cunha. Direito Tributário. São Paulo: Saraiva, 2002.

FIGUEIRÊDO, Carlos Maurício; Marcos Nóbrega. Lei de Responsabilidade Fiscal: Teoria, Jurisprudência e 130 questões. Rio de Janeiro: Impetus,2002.

GIACOMONI, James. Orçamento Público.São Paulo: Atlas,2001.

IUDíCIBUS, Sérgio de. Contabilidade Gerencial.São Paulo: Atlas,2007.

ILVO, Debus; Jeferson Vaz Morgado. Orçamento Público.Brasília: Vestcon,2004.

JUND, Sérgio. Auditoria - Conceitos, Normas, Técnicas e Procedimentos. Rio de Janeiro: Impetus, 2002.

PASCOAL, Valdecir. Direito Financeiro e Controle Externo. Rio de Janeiro: Impetus,2003. REIS, Heraldo da Costa. Contabilidade e Gestão Governamental. São Paulo: IBAM, 2004.

SILVA, Lino Martins da. Contabilidade Governamental: um enfoque administrativo. São Paulo: Atlas, 2002.

SLOMSKI, Valmor. Controladoria e Governança na Gestão Pública.São Paulo: Atlas,2005.

TROSA, Sylvie. Gestão pública por resultados. Distrito Federal: Revan, 2001.

< http://www.tce.pe.gov.br/>. Acesso em: 02 de mai 2006;

<http:// www.pernambuco.gov.br/downloads/mapas_impressão.pdf/>. Acesso em: 02 mai 2006;

<http://www.planalto.gov.br/>. Acesso em: 01 de mai 2006. 